\title{
Effect of Printing Parameters of 3D Printed PLA Parts on Mechanical Properties
}

DOI:10.36909/jer.ICMMM.15697

\author{
Jayakumar N*, Senthilkumar G, Pradeep A D \\ Department of Mechanical Engineering, Assistant Professor, Bannari Amman Institute of \\ Technology, Sathyamangalam, Tamilnadu, 638401, India \\ *Corresponding Author: er.jayakumar11@gmail.com
}

\begin{abstract}
Additive manufacturing significantly reduces the lead time of the product development cycle in the way of design trials and thus reduces delivery time to the market. The essence has been understood by many sectors including, education, manufacturing industries, automotive, medical, aerospace, consumer electronics, bio-medical and even fashion enthusiasts. It is used to prepare this PLA for the used plastics and landfills. By this way, it can reduce the plastics waste from the earth. Compare with ABS plastics, PLA plastics are cheaper. This disruptive technology going to the change the way of manufacturing goods and sets a new narrow path to the future industries. During usage of filament material, it's got failure due to not enough quality printing because of not proper process parameters. Also, the printed part does not have good surface quality. So, the PLA material requires improved mechanical properties. The objective of this study is to create 3D printed parts with good quality with the optimized process parameters. The selected process parameters are infill density (\%), Nozzle temperature $\left(^{\circ}\right)$ and print orientation. Taguchi orthogonal array (L9) design method has been chosen for generating design of experiments. The samples are produced according to its ASTM standards. The specimens were tested for identifying the mechanical properties like tensile strength, compression strength and impact strength. From the results obtained from the tests, taking the mean values and conclude the better infill density, orientation and the nozzle temperature the PLA.
\end{abstract}

Keywords: FDM; PLA; Taguchi; ASTM. 


\section{INTRODUCTION}

Polylactic Acid (PLA) is not a usual kind of thermoplastic polymers in this, it is prepared from the sustainable assets such as corn starch and sugar stick. Most of the plastics are getting from the refining process and polymerization process of non-renewable oil holdings. The PLA which are getting from biomass (for example PLA) are called as "bioplastics". Polylactic Acid are biodegradable and have the attributes like polystyrene (PS), polypropylene (PP) and polyethylene (PE). It tends to be created from previously existed assembling gears (this planned and initially utilized for the Petro-chemical industry plastics). It makes moderately cost efficient to create. As requires be, PLA have the second largest creating quantity of any bio degradable plastic (a most well-known ordinarily referred to as thermo-plastic starch). They are an immense range of utilizations for the Polylactic Acid. The exact uses are in incorporate plastic bottles and bio-degradable clinical components (for example pins, screws, poles, and plastic plates that are required to bio-degrade in 6 years). In addition, on clinical gadget models (both are bio-degradable and are perpetual). PLA contracts are under heating and are in this way appropriate for used as the psychologist wraps material. Furthermore, the similarity with Polylactic Acid melt taking into consideration for some modern applications with regards to $3 \mathrm{D}$ printing.

The advancement of combined testimony displaying boundaries for improved PLA and ABS 3D printed structures. The properties of 3D printed examples (i.e., mechanical, warm and morphological) with fluctuating preparing conditions, for example, infill design, infill thickness and infill speed, and furthermore with various printing materials. Various testing methods, for example, pliable, twisting, pressure, differential filtering calorimetry (DSC), warm gravimetric investigation (TGA), warm imaging, and examining electron microscopy (SEM) were utilized for playing out a far-reaching examination. By and large, $100 \%$ infill thickness, $90 \mathrm{~mm} / \mathrm{s}$ infill speed, $215^{\circ} \mathrm{C}$ of set spout temperature, and the direct fill design were the conceivable ideal interaction settings for the most improved exhibition of the five 
distinctive printing materials (Abeykoon, P. Sri-Amphorn, and A. Fernando et al., 2020). Optimization of Fused Deposition Modeling Processing Parameters and Design for Manufacturing approach. To examine the free impact of each preparing boundary on the mechanical properties and dimensional precision repeatability of FDM parts. An aggregate of 18 test example tests were printed utilizing fluctuating handling boundaries. Examine the repeatability and came about resilience, the components of these examples were estimated and contrasted and a 3D CAD model. It was shown that the mechanical properties are affected fundamentally constructing heading, expulsion temperature, and layer stature; and to a lesser extent on infill designs, for high infill rates examples, and printing speed. (Alafaghani, A. Qattawi, B. Alrawi, and A. Guzman et al.,2017)

Using FDM technique the impact of process parameters on the tensile properties of prepared specimen was studied. ULTEM 9085 is used with full factorial design of experiment. There are five parameters considered for examination like air gap, raster width, raster angle, contour number and contour width. It is noted that only one parameter (raster angle) significantly influenced the tensile properties of the material among the considered parameters. (W. Gebisa and H. G. Lemu et al., 2019)

To accomplish 3D printing of PEEK the FDM technique is used. To reproduce the dissolving conditions and fluidity of PEEK in a flow channel, the Finite Element Analysis (FEA) was used. The reenactments results were additionally investigated to instruct the arrangement of future printing structure and upgrade the printing limits. Moreover, a few FDM tests were performed to consider the impacts of various printing limits, including the printing temperature, printing speed, and printing layer thickness, on the mechanical properties, microstructure, and surface nature of printed PEEK parts. The results suggested that using a higher warming temperature of $440{ }^{\circ} \mathrm{C}$, a printing rate of $20 \mathrm{~mm} / \mathrm{s}$, and a little printing layer thickness of $0.1 \mathrm{~mm}$ can improve the thickness of PEEK parts, diminish inner imperfections, 
fortify restricting between 3D printed layers and infill filaments, and lessen surface unpleasantness. (P. Wang, B. Zou, H. Xiao, S. Ding, and C. Huang et al., 2019) In the writing there are numerous works concerning the mechanical portrayal of the PLA at the same time, because of the regular orthotropy of the FDM interaction and, most importantly, to the discovered impact of the specific specialized framework with which the activities are performed, it is important to describe the expelled material through various metrological procedures. 6 examples for every course (level, on side, vertical, figure 2) have been printed for a sum of 18 examples for the static elastic test. Through this subjective examination of the area of the crack point, an alternate conduct between vertical examples and the other two sets (on side and even) is apparent. (D. Corapi, G. Morettini, G. Pascoletti, and C. Zitelli et al., 2019)

\section{POLYLACTIC ACID}

Polylactic Acid are essentially made from two distinct cycles: they are building up and polymerization. They are most widely recognized in polymerization method is called as ringopening polymerization. It is an interaction that use the metal impet use in mix with the lactide to make the biggest PLA atoms. The building up interaction is comparative with important contrast being in the temperature during the strategy and the result are delivered as an outcome of that response. Since we understand that what it is to be utilized for, we analyze a portion of a critical property of Polylactic Acid. PLA is called as "thermoplastic" polyester. Thermoplastic materials become fluid at the time of dissolving point (150-1600C on account of PLA). A significant valuable property of the thermoplastics is that this can be warm to their liquefying point, and then cooled, and warm again without huge debasement. Rather than consuming, thermoplastics like Polylactic Acid condense, which permits them to be effectively infusion formed and afterward in this way reused. Paradoxically, thermoset plastics must be warmed once (normally during the infusion shaping cycle). PLA is its biodegradable nature and the maintainable interaction by which it is made, settling on it the 
harmless to the ecosystem decision of plastic. Table 1 . Shows the properties of polylactic acid.Properties of polylactic acid: Diameter: $1.75 \mathrm{~mm}+/-0.02 \mathrm{~mm}$, Printing Temperature: $190-210^{\circ} \mathrm{C}$ and Bed Temperature: $60^{\circ} \mathrm{C}$

Table 1. Properties of Polylactic acid

\begin{tabular}{|l|l|l|l|}
\hline Property & Value & Units & Testmethod \\
\hline Generalproperties & 1.24 & $\mathrm{~g} / \mathrm{cm}^{3}$ & ASTMD792 \\
\hline Specificgravity & 3600 & $\mathrm{MPa}$ & ISO178 \\
\hline Mechanicalproperties & 108 & $\mathrm{MPa}$ & ISO178 \\
\hline Flexuralelasticmodules & 85 & Sh D & ASTMD2240 \\
\hline Flexuralstrength & \multicolumn{5}{|l|}{} \\
\hline Hardness.ShD & 56 & ${ }^{\circ} \mathrm{C}$ & ISO75/2B \\
\hline Thermalproperties & \multicolumn{5}{|l|}{} \\
\hline Heat distortion & \multicolumn{5}{|l|}{} \\
\hline temperatureHDT B(0.45MPa) & $145-160$ & ${ }^{\circ} \mathrm{C}$ & ASTMD3418 \\
\hline Meltingtemperature & $56-64$ & ${ }^{\circ} \mathrm{C}$ & ASTMD3418 \\
\hline Gas distortion & & & \\
\hline
\end{tabular}

\section{SPECIMEN DESIGN}

ASTM D638 Type 1 for the tensile test of the PLA polymers as shown in Figure 1. ASTM standards of ASTM D256 - 10 for the impact test as shown in Figure 2. and ASTM D695 for the compression test.

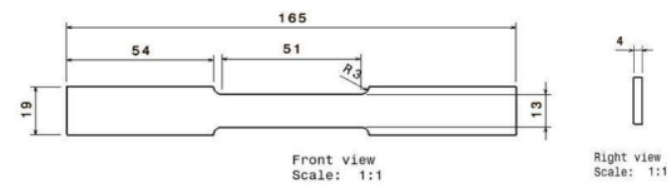

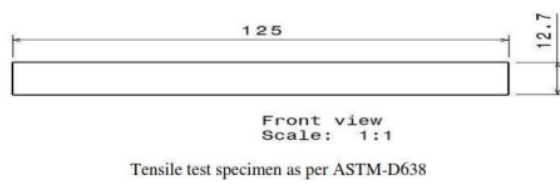

Figure 1. Tensile test specimen-ASTM

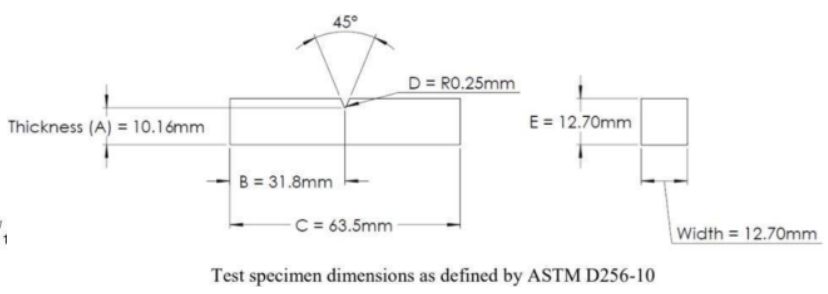

Figure 2. Impact test specimen-ASTM

After the selection of the parameters the test, the samples are segregated and differentiated by 
using Taguchi method. The specimens are to be designed first as CAD file and then are to be converted to 3D printing format. The specimens are prepared based on the types of mechanical tests to be taken. As this is a polymer composite, their ASTM standards design can be in consideration while drafting the design. The design for specimen is done using SOLIDWORKS software and set with tolerance limit in consideration with thermal expansion while 3D printing process. Figures $3,4 \& 5$ shows the design of tensile test, impact test and compression test specimen.

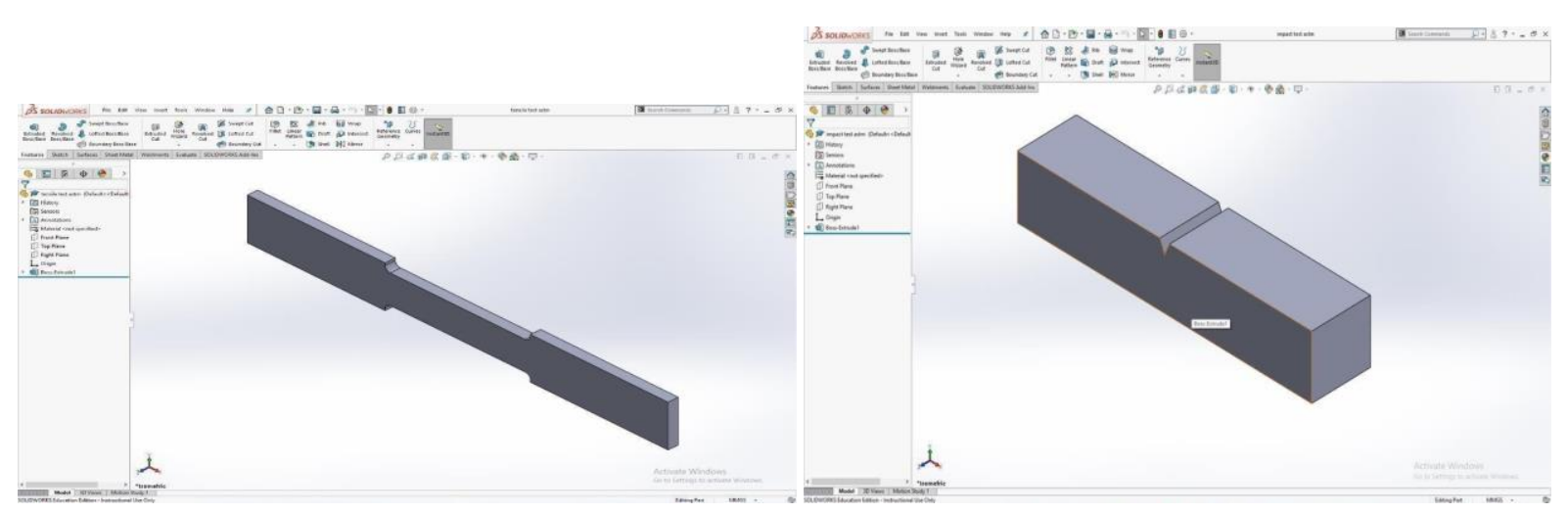

Figure 3. Tensile test specimen

Figure 4. Impact test specimen

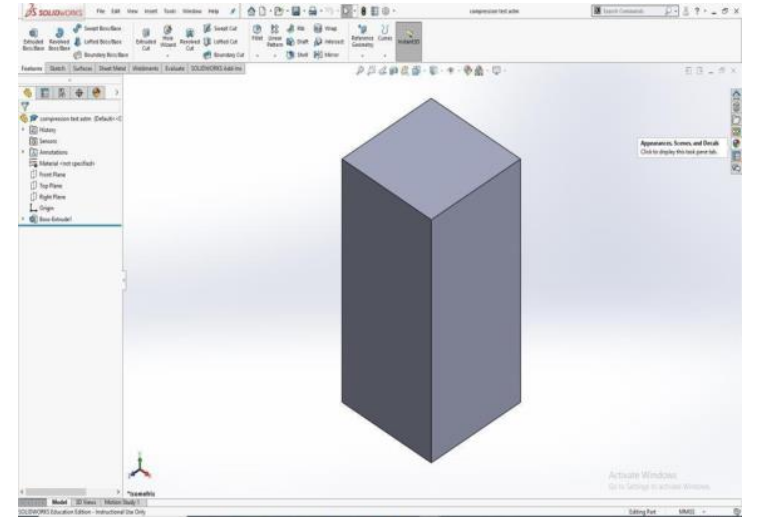

Figure 5. Compression test specimen

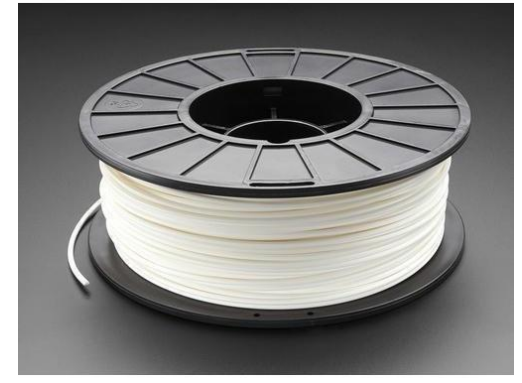

Figure 6. PLA Filament spool

\section{FABRICATION OF SPECIMEN}

The fabrication of specimen is done by using 3D printing technique. Creality 3D ender printer has used for this process due to its high accuracy in printing and reliability. PLA material of high quality and white color (filament type) weighing $1 \mathrm{~kg}$ is used in the fabrication process. Figure 6. illustrates the PLA material used in the process. Creality machine is cleaned 
thoroughly before the printing process to ensure proper printing and the nozzle has air blown to remove particles present in it.

3D printer fiber spools come in a wide range of styles and sizes. Most 3D printers will acknowledge spools that fall inside a bunch of industry acknowledged guidelines. Our spools are intended to fit most 3D printers that acknowledge a standard spool size.

Bigger fiber spools take into account consistent 3D printing without changing out the spool and intrude on prints. A greater spool is ideal for a bigger form that necessary more 3D printer fiber. This may even be ideal for more modest prints on the off chance that you are burnt out on changing out spools so frequently.

\section{DESIGN OF EXPERIMENTS}

In this paper, the Taguchi Method is used for the better selection of the specimens as shown in Table 2. The L9 array is used because of the three parameters such as infill density, print orientation and nozzle temperature. Each test is having 9 specimens. So, a total of 27 specimens has to be prepared. In this, nozzle temperature changes are done at the $3 \mathrm{D}$ printing machine only.

Table 2. Taguchi L9 table

\begin{tabular}{|c|c|c|c|}
\hline Trial & A & B & C \\
\hline 1 & 1 & 1 & 1 \\
\hline 2 & 1 & 2 & 2 \\
\hline 3 & 1 & 3 & 3 \\
\hline 4 & 2 & 1 & 3 \\
\hline 5 & 2 & 2 & 1 \\
\hline 6 & 2 & 3 & 3 \\
\hline 7 & 3 & 1 & 1 \\
\hline 8 & 3 & 2 & 2 \\
\hline 9 & 3 & 3 & \\
\hline
\end{tabular}

\section{EXPERIMENTAL PROCEDURE}

After the fabrication and post treatment of prepared specimen they are subjected to various Mechanical tests such Tensile test, Impact test, compression test to better understand the 
Mechanical behaviour of the prepared specimen. The tests are done as per the ASTM standards and with utmost care to undermine the best results possible. The results are noted down from each test taken and graphs are plotted based on it. The graphs would give us a glimpse of how the different specimen behaved for different tests taken and find out the better combination for making a better product. Further on the note results and conclusion can be drawn out.

\section{TENSILE TEST}

Tensile test is taken out for the specimen to study their breaking nature and elongation properties. FIE Universal Tensile tester (Figure 7.) was used in the process of testing. The specimens were fixed between the top and bottom jaws of the machine. As the test process starts, the upper jaw moves upward while the lower jaw remains constant. At certain point the specimen breaks, indicating its max breaking capacity. The results are all obtained in the software and graphs are also generated for the same and the results can be customized based on the requirement with graph plotting too. Figure 8 . shows the different tensile test specimen before the test is taken.

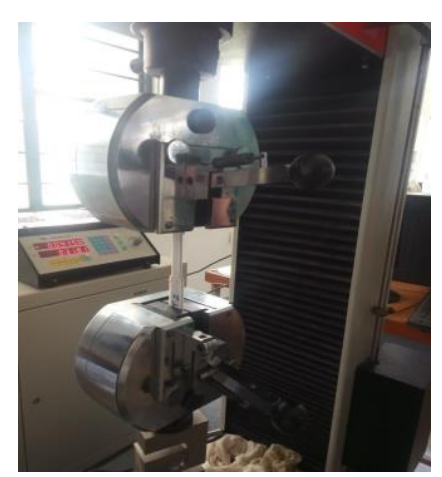

Figure 7. FIE Tensile Testing Machine

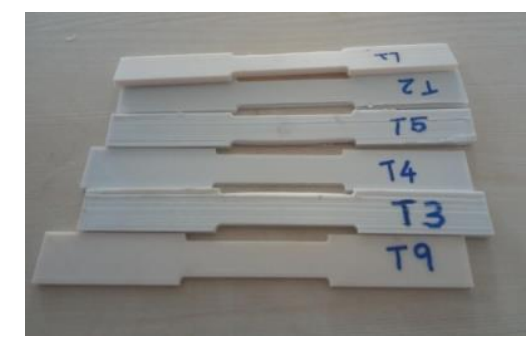

Figure 8. Tensile test specimen before testing

\section{IMPACT TEST}

Impact test of specimen are taken out to study the energy absorbing capacity of the polymer composite. The test taken here is Izod Impact test for the specimen. The specimen is placed in the bottom area of the stand between the verticals. The striker of certain load capacity is taken 
and placed at certain height for release.

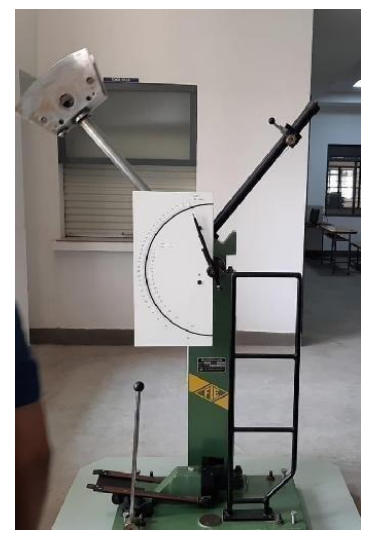

Figure 9. Impact Testing Machine

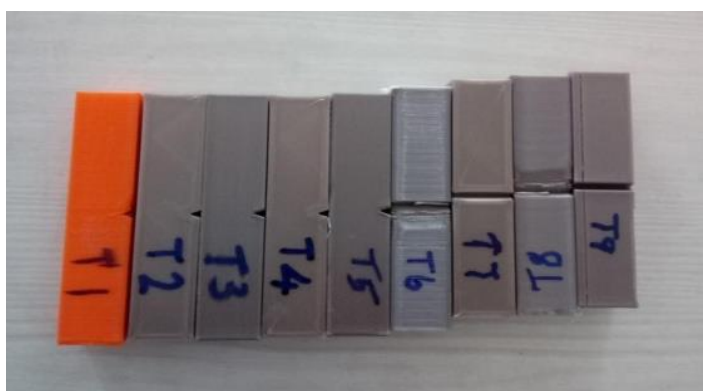

Figure 10. Impact test specimen before testing

The striker is released down for testing and it hits hard at the specimen, thus breaking it into two separate pieces. Figure 9. shows an Impact testing machine in operation. The impact energy value is shown by the dial as soon as the striker hits the specimen. The value is measured in Joules and it noted down for further study. Figure 10. shows the typical specimens used for the Impact test. These are mechanically operated machines and the values obtained are also in a mechanical dial, thus accuracy of measurement may slightly differ from digitized one.

\section{COMPRESSION TEST}

Compression testis done in the compression testing machine. The specimens are cube like structure as shown in Figure 11. The sample is placed in between the two hydraulic operated weights. The lower one is static and it acts like a base for the specimens. The upper one is movable and the values are taken from that weight only as shown in Figure 12. The testing process of compression for the polymers are very quick compare to other metal alloys.
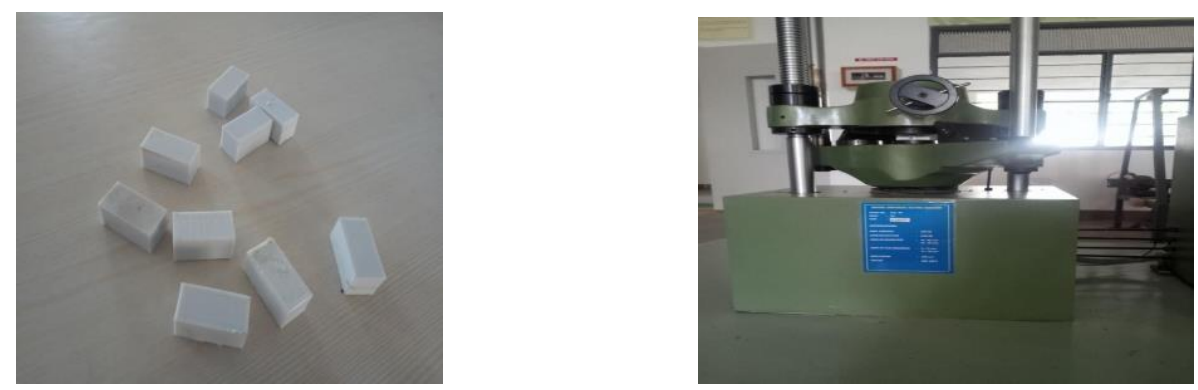
Figure 11. Compression test specimen before test Figure 12. Compression Testing Machine From various experimental study conducted, cost for every process and material used is also important.

\section{RESULTS AND DISCUSSION}

\section{MECHANICAL TEST RESULTS}

This type of tests helps to understand the strength and ductility of specimens developed.

\section{TENSILE TEST}

Figure 13. Shows the tensile test specimen after testing.

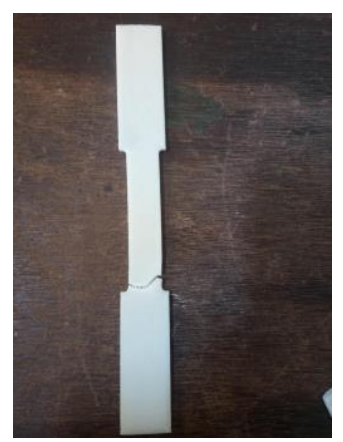

Figure 13. Tensile test specimen after testing

\section{IMPACT TEST}

The test specimen is prepared according to its ASTM standards and Izod Impact Test is carried out and the results were plotted in the Table 3 .

Table 3. Izod Impact Test Results

\begin{tabular}{|c|c|}
\hline Impacttest & \\
\hline Trial & jol \\
\hline 1 & 2 \\
\hline 2 & 6 \\
\hline 3 & 2 \\
\hline 4 & 2 \\
\hline 5 & 10 \\
\hline 6 & 2 \\
\hline 2 & 7 \\
\hline 8 & 3 \\
\hline 9 & 4 \\
\hline
\end{tabular}


The above result values show the results of three impact test specimen. Figure 14. shows the impact test specimen after tested.

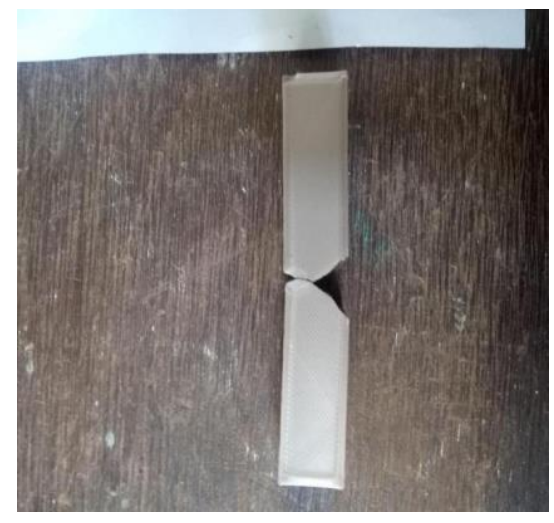

Figure 14. Impact Strength Tested Specimen

\section{COMPRESSION TEST}

The test specimen is prepared according to its ASTM standards and compression test is carried out and the results were shown in the Table 4. 
Table 4. Compression Test Results

\begin{tabular}{|r|l|c|c|c|}
\hline \multicolumn{5}{|c|}{ CompressionTest } \\
\hline Trial & $\begin{array}{l}\text { Peak } \\
\text { Load }\end{array}$ & Displacement & $\begin{array}{c}\text { End } \\
\text { Displacement }\end{array}$ & $\begin{array}{l}\text { Breaking } \\
\text { Load }\end{array}$ \\
\hline 1 & 8.94 & 2.8 & 6 & 4.8 \\
\hline 2 & 7.62 & 0.3 & 4.3 & 3.46 \\
\hline 3 & 7.78 & 0.3 & 7.2 & 3.86 \\
\hline 4 & 8.44 & 0.2 & 6.7 & 3.84 \\
\hline 5 & 7.48 & 0.8 & 5.6 & 3.52 \\
\hline 6 & 9.7 & 0.6 & 8.5 & 4.16 \\
\hline 7 & 9.063 & 0.4 & 1.9 & 3.76 \\
\hline 8 & 9.96 & 4.4 & 4.5 & 4.16 \\
\hline 9 & 9.902 & 0.8 & 1.5 & 4.36 \\
\hline
\end{tabular}

The above result table shows compression strength of the specimens that prepared. Figure 15 . shows the compression test specimen after tested. In Table 5. All the tested results were tabulated.

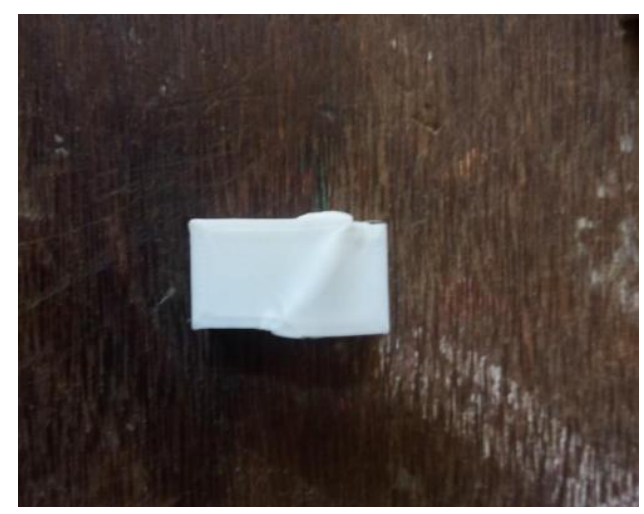

Figure 15. Compression Strength Tested Specimen 
Table 5. Tested results

\begin{tabular}{|c|c|c|c|c|c|c|}
\hline $\begin{array}{c}\text { Tria } \\
1\end{array}$ & $\begin{array}{l}\text { Infill } \\
\text { Density ( } \\
\left.\frac{\circ}{0}\right)\end{array}$ & $\begin{array}{c}\text { Nozzle } \\
\text { Temperatu } \\
\text { re }\end{array}$ & $\begin{array}{l}\text { Print } \\
\text { Orientati } \\
\text { on }\end{array}$ & $\begin{array}{c}\text { Tensile } \\
\text { strength } \\
\left(\mathrm{kn} / \mathrm{mm}^{\wedge}\right.\end{array}$ & $\begin{array}{c}\text { Compressi } \\
\text { on } \\
\text { strength }\end{array}$ & $\begin{array}{l}\text { Impact } \\
\text { strength } \\
\left(\mathrm{kn} / \mathrm{mm}^{\wedge}\right.\end{array}$ \\
\hline 1 & 30 & 190 & 90 & 0.004 & 4.18 & 2 \\
\hline 2 & 30 & 200 & 0 & 0.02 & 3.46 & 6 \\
\hline 3 & 30 & 210 & 180 & 0.016 & 3.86 & 2 \\
\hline 4 & 40 & 190 & 0 & 0.021 & 3.84 & 2 \\
\hline 5 & 40 & 200 & 180 & 0.022 & 3.96 & 10 \\
\hline 6 & 40 & 210 & 90 & 0.004 & 4.16 & 2 \\
\hline 7 & 50 & 190 & 180 & 0.014 & 3.76 & 7 \\
\hline 8 & 50 & 200 & 90 & 0.009 & 4.16 & 3 \\
\hline 9 & 50 & 210 & 0 & 0.022 & 4.36 & 4 \\
\hline
\end{tabular}

\section{TENSILE TEST TAGUCHI ANALYSIS}

Figure 16. (a) \& (b) shows the taguchi analysis for tensile strength.

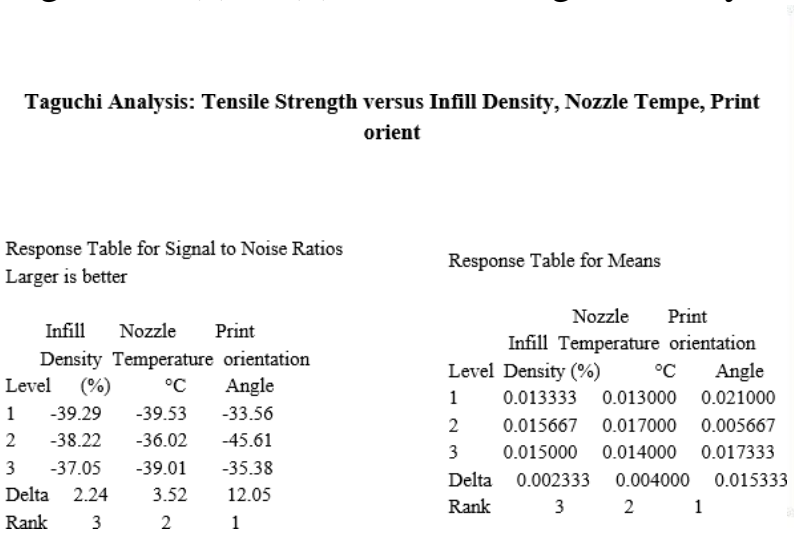

Figure 16. (a) Taguchi analysis

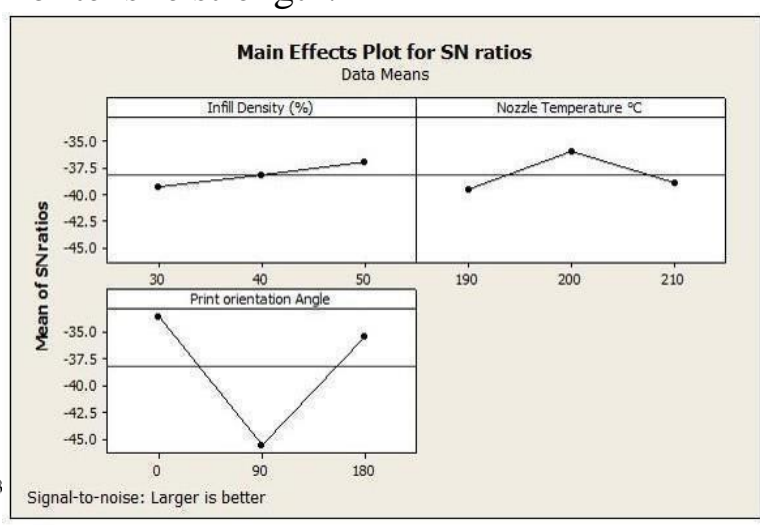

(b) Tensile strength versus infill density

\section{COMPRESSION TEST TAGUCHI ANALYSIS}

Figure 17. (a) \& (b) shows the taguchi analysis for compression strength.

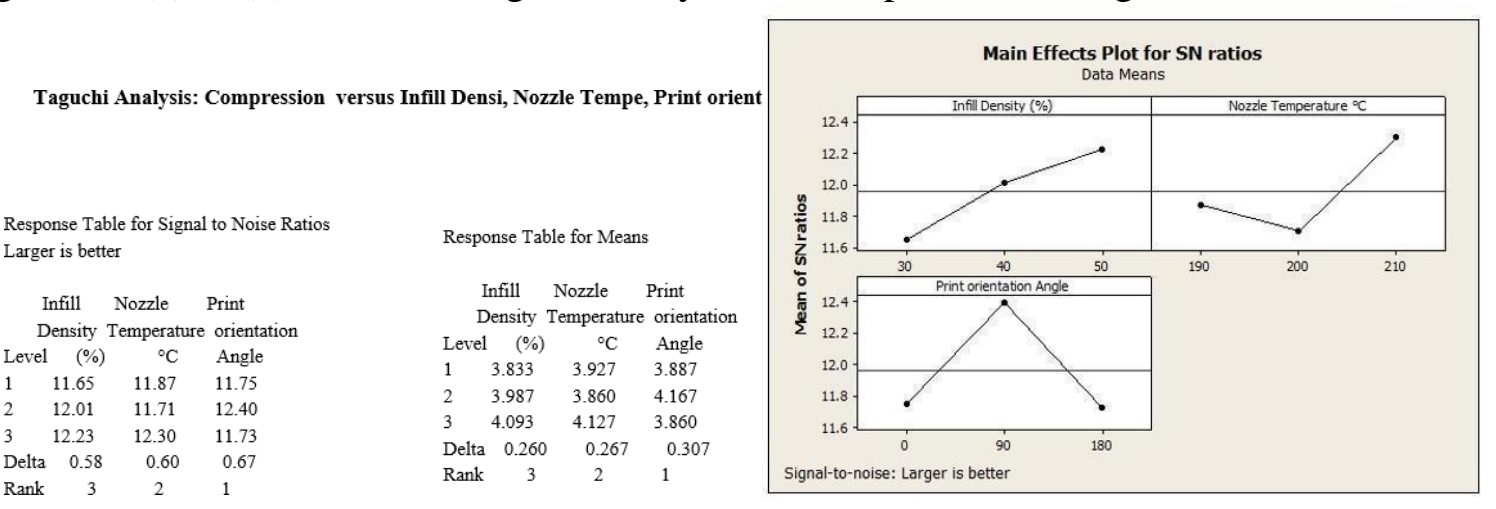


Figure 17. (a) Taguchi analysis

(b) Compression strength versus infill density

\section{IMPACT TEST TAGUCHI TEST}

Figure 18. (a) \& (b) shows the taguchi analysis for impact strength.

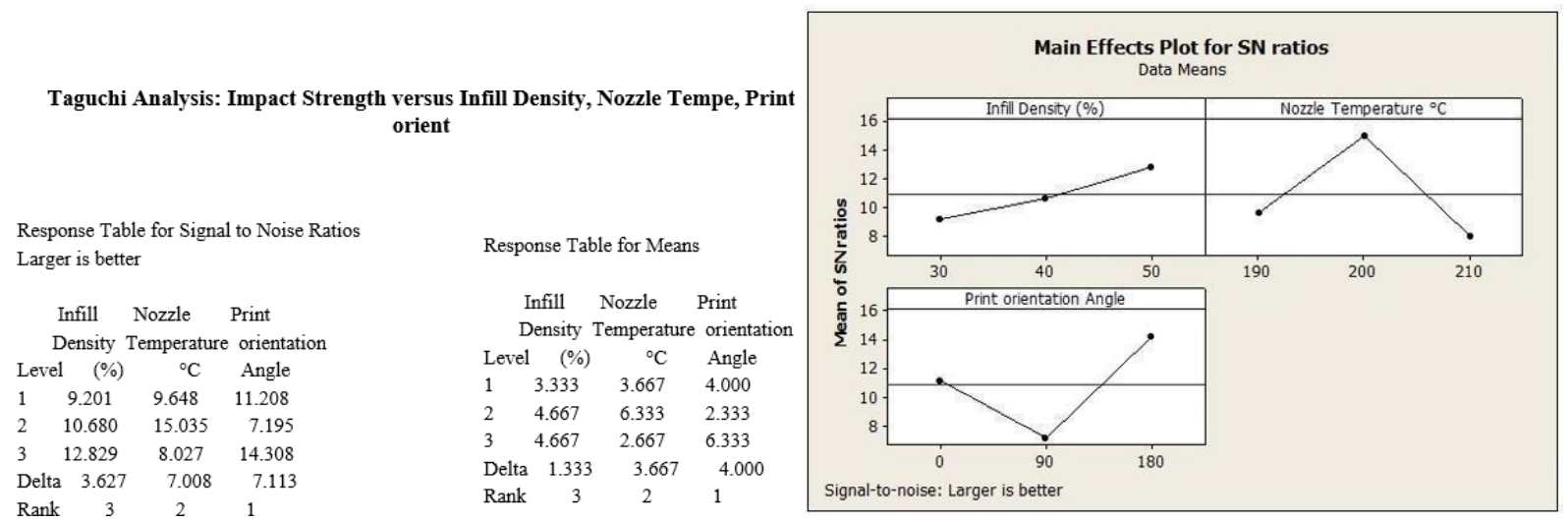

Figure 18. (a) Taguchi analysis

(b) Impact strength versus infill density

\section{CONCLUSION}

Now a days 3D printed component is most widely used for various purposes, but its properties like Tensile, compression, Impact, etc. can be improved by using of various methods. In this project work the new combinations are developed and various mechanical tests are done and obtained results are compared and listed below:

From all the results of mean values of specimens, by using the taguchi analysis method, it makes the conclusion that at the infill density of $50 \%$, in the nozzle temperature of $200 \%$ and at the print orientation of horizontal position, it can create a good and strong product compare to other combination. All this test helps in better understanding of components under the influence of infill density, nozzle temperature and the print orientation. 


\section{REFERENCES}

Abeykoon, P. Sri-Amphorn, and A. Fernando, "Optimization of fused deposition modeling parameters for improved PLA and ABS 3D printed structures," Int. J. Light. Mater. Manuf., vol. 3, no. 3, pp. 284-297, 2020, doi: 10.1016/j.ijlmm.2020.03.003.

Alafaghani, A. Qattawi, B. Alrawi, and A. Guzman, "Experimental Optimization of Fused Deposition Modelling Processing Parameters: A Design- for-Manufacturing Approach,” Procedia Manuf., vol. 10, pp. 791-803, 2017, doi: 10.1016/j.promfg.2017.07.079. W. Gebisa and H. G. Lemu, "Influence of 3D printing FDM process parameters on tensile property of ultem 9085," Procedia Manuf., vol. 30, pp. 331-338, 2019, doi: 10.1016/j.promfg.2019.02.047.

P. Wang, B. Zou, H. Xiao, S. Ding, and C. Huang, "Effects of printing parameters of fused deposition modeling on mechanical properties, surface quality, and microstructure of PEEK,” J. Mater. Process. Technol., vol. 271, no. September 2018, pp. 62-74, 2019, doi: 10.1016/j.jmatprotec.2019.03.016.

D. Corapi, G. Morettini, G. Pascoletti, and C. Zitelli, "Characterization of a polylactic acid (PLA) produced by Fused Deposition Modeling (FDM) technology," Procedia Struct. Integr., vol. 24, no. 2019, pp. 289-295, 2019, doi: 10.1016/j.prostr.2020.02.026.

S. Anand Kumar and Y. Shivraj Narayan, Tensile testing and evaluation of 3D-printed PLA specimens as per ASTM D638 type IV standard. Springer Singapore, 2019.

Carmen R. Rocha. Angel R. Torrado Perez, David, A. Roberson, Ryan B.Wicker. and Corey M. Shemelya. (2014), "Novel ABS-based binary andternary polymer blends for material extrusion 3D printing”, Journal of Material Research, Vol. 29, No. 17, pp. 18591866.

Chaithanyan, C. Panneerselvam, T. Raghuraman, S. and VijayaRamnath, B. (2014), "Investigation of Tensile behaviour of Sisal and Coir ReinforcedHybrid Composites using 
Vinyl Ester Resin”, Applied Mechanics and Materials, Vol.591, pp.146-149.

Babagowda, R. S. Kadadevara Math, R. Goutham, and K. R. Srinivas Prasad, "Study of Effects on Mechanical Properties of PLA Filament which is blended with Recycled PLA Materials," IOP Conf. Ser. Mater. Sci. Eng., vol. 310, no. 1, 2018, doi: 10.1088/1757899X/310/1/012103. 